\title{
Characterization of the Natural History of Extracellular Matrix Production in Tissue-Engineered Vascular Grafts during Neovessel Formation
}

\author{
Yuji Naito a, c Misty Williams-Fritze ${ }^{d}$ Daniel R. Duncan ${ }^{a}$ Spencer N. Church ${ }^{a}$ \\ Narutoshi Hibino ${ }^{\text {a, c }}$ Joseph A. Madrib Jay D. Humphrey ${ }^{\mathrm{e}}$ Toshiharu Shinoka ${ }^{c}$ \\ Christopher K. Breuer ${ }^{a}$ \\ Departments of a Surgery, ${ }^{b}$ Pathology and ${ }^{c}$ Cardiac Surgery, and d Section of Comparative Medicine, Yale University \\ School of Medicine, and e Department of Biomedical Engineering, Yale School of Engineering and Applied Science, \\ New Haven, Conn., USA
}

\section{Key Words}

Tissue engineering $\cdot$ Extracellular matrix $\cdot$ Vascular remodeling $\cdot$ Collagen $\cdot$ Elastin

\begin{abstract}
Background: The extracellular matrix (ECM) is a critical determinant of neovessel integrity. Materials and Methods: Thirty-six (polyglycolic acid + polycaprolactone and poly lactic acid) tissue-engineered vascular grafts seeded with syngeneic bone marrow mononuclear cells were implanted as inferior vena cava interposition grafts in C57BL/6 mice. Specimens were characterized using immunohistochemical staining and qPCR for representative ECM components in addition to matrix metalloproteinases (MMPs). Total collagen, elastin, and glycosaminoglycan (GAG) contents were determined. MMP activity was measured using zymography. Results: Collagen production on histology demonstrated an initial increase in type III at 1 week followed by type I production at 2 weeks and type IV at 4 weeks. Gene expression of both type I and type III peaked at 2 weeks, whereas type IV
\end{abstract}

Yuji Naito and Misty Williams-Fritze are co-first authors. continued to increase over the 4-week period. Histology demonstrated fibrillin-1 deposition at 1 week followed by elastin production at 4 weeks. Elastin gene expression significantly increased at 4 weeks, whereas fibrillin-1 decreased at 4 weeks. GAG demonstrated abundant production at each time point on histology. Gene expression of decorin significantly increased at 4 weeks, whereas versican decreased over time. Biochemical analysis showed that total collagen production was greatest at 2 weeks, and there was a significant increase in elastin and GAG production at 4 weeks. Histological characterization of MMPs showed abundant pro-

\begin{tabular}{ll} 
Abbreviations used in this paper \\
\hline BMC & bone marrow-derived mononuclear cells \\
ECM & extracellular matrix \\
GAG & glycosaminoglycan \\
IHC & immunohistochemistry \\
IVC & inferior vena cava \\
MMP & matrix metalloproteinase \\
P(CL/LA) & polycaprolactone and poly lactic acid \\
PGA & polyglycolic acid \\
TEVG & tissue-engineered vascular graft \\
TIMPs & tissue inhibitors of metalloproteinases
\end{tabular}

\section{KARGER}

(๑) 2011 S. Karger AG, Basel

Fax +4161306 1234

E-Mail karger@karger.ch

www.karger.com
Accessible online at: www.karger.com/cto
Dr. Christopher K. Breuer

Department of Surgery, Yale University School of Medicine

333 Cedar Street, PO Box 208062

New Haven, CT 06520 (USA)

Tel. +1 203785 2701, E-Mail Christopher.Breuer@ Yale.edu 
duction of MMP-2 at each time point, while MMP-9 decreased over the 4-week period. Gene expression of MMP-2 significantly increased at 4 weeks, whereas MMP-9 significantly decreased at 4 weeks. Conclusions: ECM production during neovessel formation is characterized by early ECM deposition followed by extensive remodeling.

Copyright ๑ 2011 S. Karger AG, Basel

\section{Introduction}

We developed the first tissue-engineered vascular graft (TEVG) based on a biodegradable scaffold to be successfully used in humans [Shin'oka et al., 2001]. In our initial clinical pilot study we evaluated the use of TEVG in congenital heart surgery [Shin'oka et al., 2005; Hibino et al., 2010]. The results of this clinical study provide evidence that TEVG are the first man-made vascular grafts with demonstrated growth potential in humans, making them uniquely suited for use in children [Shin'oka et al., 2005; Brennan et al., 2008]. Additionally, TEVG were found to have a reasonable safety and efficacy profile with no graft-related deaths or graft failures up to 6 years after implantation [Shin'oka et al., 2005]. The primary graftrelated complication was stenosis [Hibino et al., 2010]. The development of an improved TEVG will be predicated on our understanding of the process of neovessel formation and the development of TEVG stenosis.

Our TEVG is created by seeding autologous bone marrow mononuclear cells (BMC) onto a biodegradable tubular scaffold fabricated from polyglycolic acid fibers (PGA) coated with a 50:50 copolymer of polycaprolactone and poly lactic acid [P(CL/LA)] [Matsumura et al., 2003, 2006]. The seeded scaffold is incubated for a short period of time prior to implantation in vivo. The scaffold provides sites for cell attachment and space for neotissue formation. As the scaffold degrades, neotissue forms, ultimately creating an autologous neovessel (without any synthetic components) that resembles a native blood vessel [Brennan et al., 2008]. Neovessel formation is a dynamic process characterized by progressive degradation of the scaffold due to hydrolysis, cellular infiltration into the scaffold, and extracellular matrix (ECM) deposition and remodeling.

The primary components of the ECM include collagen, elastin, and glycosaminoglycans (GAG) [Brennan et al., 2008]. The composition of the ECM is important because it is the primary determinant of the neovessel's biomechanical properties. Abnormal ECM formation can alter the biomechanical forces applied to the neotissue and can lead to the development of aneurismal dilation or the formation of stenosis, which can lead to graft failure. In order to investigate the cellular and molecular mechanisms underlying neovessel formation, we developed a miniaturized version of our TEVG that allows for vascular implantation in a murine model [Roh et al., 2008]. The C57BL/6 murine model is a validated model for investigating vascular neotissue formation and faithfully recapitulates the results of our clinical trial evaluating the use of TEVG in humans [Roh et al., 2010]. We have used the murine model to extensively characterize the cellular composition of the neotissue over time [Roh et al., 2010]. In this investigation we performed an extensive qualitative and quantitative assessment of ECM development in our TEVG over a 4 -week time course in C57BL/6 mice as a first step towards better understanding ECM formation in TEVG.

\section{Materials and Methods}

\section{TEVG Fabrication}

Tubular scaffolds were constructed from sheets of nonwoven PGA felt (Concordia Fibers, Coventry, R.I., USA) sealed with 50:50 copolymer sealant solution composed of $\varepsilon$-caprolactone and L-lactide $[\mathrm{P}(\mathrm{CL} / \mathrm{LA})]$ (Absorbable Polymers International, Birmingham, Ala., USA) as previously described [Nelson et al., 2008; Roh et al., 2008]. The internal diameter of each scaffold was 0.9 $\mathrm{mm}$, and the length of each scaffold was approximately $3.0 \mathrm{~mm}$.

\section{BMC Seeding}

Bone marrow was harvested from gender-matched syngeneic C57BL/6 mice. BMC were isolated from bone marrow by performing density gradient centrifugation using Histopaque-1083 (Sigma). One million BMC were statically seeded onto each scaffold and incubated in RPMI-1640 culture media overnight at $37^{\circ} \mathrm{C}$ and $5 \% \mathrm{CO}_{2}$.

\section{Animal Model}

Thirty-six female C57BL/6 mice at approximately 8 weeks of age were obtained from The Jackson Laboratory (Bar Harbor, Me., USA) for this study. All experimental procedures were approved by the Yale University Institutional Animal Care and Use Committee. Seeded TEVGs were implanted as inferior vena cava (IVC) interposition grafts using microsurgical techniques as previously described [Roh et al., 2008]. Tissue-engineered neovessels were harvested 7 days $(\mathrm{n}=12), 14$ days $(\mathrm{n}=12)$, and 28 days $(\mathrm{n}=$ 12) after surgery. Fresh specimens were used for molecular, enzymatic, and biochemical analysis ( 9 animals per time point). Pressure-fixed specimens were used for morphological studies (3 animals per time point).

\section{Ultrasound Measurement of TEVG}

A high-frequency ultrasound biomicroscopy system (Vevo 770; Visualsonics, Toronto, Ont., Canada) equipped with an RMV-704 transducer was used to measure the neovessel internal diameter for all mice at postoperative days 7, 14, and 28 . 


\section{Histology}

Explanted TEVG samples were pressure fixed in 10\% formalin and embedded in paraffin. Five-micrometer sections were stained using standard techniques for Masson's trichrome, Elastica van Gieson, and Alcian blue stains. Masson's trichrome staining was used to demonstrate collagen fibers in green and cellular infiltrate in bright red. Picrosirius red staining was used to show the difference in distribution between large and thin collagen fibers.

\section{Immunohistochemistry}

Tissue sections were deparaffinized, rehydrated, and blocked for endogenous peroxidase activity and then for nonspecific staining. Primary antibodies used included: collagen I, III [Madri et al., 1980], and IV (Santa Cruz); Fibrillin-1 (Abcam); matrix metalloproteinase (MMP)-2 (Millipore); MMP-9 (R\&D Systems); $\alpha$ smooth muscle actin (Dako), and CD31 (Abcam). For immunohistochemistry (IHC), antibody binding was detected using biotinylated secondary antibodies, followed by binding of streptavidinHRP. Color development was performed by chromogenic reaction with 3,3-diaminobenzidine (Vector). Nuclei were counterstained with hematoxylin. For immunofluorescence detection, goat-antirabbit IgG-Alexa Fluor 568 (Invitrogen) or a goat-anti-mouse IgGAlexa Fluor 488 (Invitrogen) was used with subsequent 4',6diamidino-2-phenylindole (DAPI) nuclear counterstaining.

\section{Scaffold Degradation in vivo}

In order to determine the in vivo degradation rate of scaffold polymer, the histologic samples were observed under a polarized microscope in which remaining scaffold components were clearly demarcated by their birefringence.

\section{Biochemical Analysis}

The entire length of each fresh specimen TEVG ( 3 animals for each time point) was homogenized and lyophilized for quantitative biochemical analysis.

\section{Collagen Quantification}

The collagen content was determined by measuring the hydroxyproline content. Dry weights of lyophilized samples $(n=3$ for each time point) were measured and transferred to $1.8-\mathrm{ml}$ cryo tubes containing $100 \mu \mathrm{l}$ of $2 \mathrm{~N} \mathrm{NaOH}$. In separate tubes, 0 (blank), $5,10,15$, and $20 \mu \mathrm{g}$ of hydroxyproline standard (Sigma) dissolved in $100 \mu l 2 \mathrm{~N} \mathrm{NaOH}$ were prepared to establish a standard curve for each experiment. Samples were hydrolyzed at $120^{\circ} \mathrm{C}$ for $30 \mathrm{~min}$ and then oxidized by adding $450 \mu \mathrm{l}$ of chloramine-T reagent and incubating at room temperature for $25 \mathrm{~min}$. After oxidation, a chromophore was developed by adding $500 \mu \mathrm{l}$ Ehrlich's reagent to each sample and incubating at $65^{\circ} \mathrm{C}$ for $20 \mathrm{~min}$. The absorbance of each standard and the samples was measured at $550 \mathrm{~nm}$ by spectrometry. The collagen content was calculated by multiplying the hydroxyproline content by 7.0 as previously described [Samuel, 2009]. Collagen production for each sample was determined by dividing the total collagen content by the total weight of each sample.

\section{Elastin Quantification}

The elastin content was determined using a Fastin ${ }^{\mathrm{TM}}$ colorimetric assay (Biocolor Assays, Inc.). Dry weights of lyophilized samples were measured and transferred to $1.5-\mathrm{ml}$ microcentrifuge tubes containing $100 \mu l 0.25 \mathrm{M}$ oxalic acid. The tubes were then placed into a boiling water bath for $60 \mathrm{~min}$ to convert in- soluble elastin to water-soluble $\alpha$-elastin. A standard curve was created using controls from a kit. The elastin content in each sample was detected with spectrometry at $513 \mathrm{~nm}$ after precipitation and dye binding of $\alpha$-elastin.

\section{GAG/Proteoglycan Quantification}

The GAG content was determined using a Blyscan ${ }^{\mathrm{TM}}$ colorimetric assay (Biocolor Assays). Dry weights of lyophilized samples were measured and digested in papain extraction reagent. A standard curve was created using controls from a kit. The GAG content in each sample was detected with spectrometry at $656 \mathrm{~nm}$ after precipitation and dye binding of GAG.

SDS-PAGE Zymography for Detection of MMP-2 and MMP-9

Tissue samples were homogenized in extraction buffer (Triton $\mathrm{X}-100)$. Homogenized tissue was centrifuged and supernatants recovered for analysis. Protein concentrations in lysates were determined against a standard curve (Bio-Rad, Hercules, Calif., USA). Thirty-microgram samples were mixed 1:2 with zymography sample buffer (Bio-Rad) and electrophoresed under nonreducing conditions on zymography gels (Readygel; Bio-Rad) for up to $2 \mathrm{~h}$. Following electrophoresis, gels were placed in renaturation buffer (Triton X-100) for $60 \mathrm{~min}$ to remove SDS and then incubated at $37^{\circ} \mathrm{C}$ overnight in $\mathrm{Ca}^{2+}$ buffer. Controls were preincubated with $20 \mathrm{~mm}$ EDTA for $1 \mathrm{~h}$, and $20 \mathrm{~mm}$ EDTA was also added to the substrate. Gels were stained the following day with $0.3 \%$ Coomassie blue for $1 \mathrm{~h}$ and then destained for up to $2 \mathrm{~h}$. MMPs appear as clear bands on a blue background. Bands were compared to MMP-2 and MMP-9 standards (Chemicon).

\section{In situ Zymography}

In order to detect localization of gelatinolytic activity, in situ zymography was performed. Gelatin DQ is linked to a quenched FITC that is released upon gelatin digestion. Ten-micrometerthick sections were cut from the same tissue which was used for substrate zymography. The cryosections were air dried for $30 \mathrm{~min}$ and then washed in PBS. Substrate was prepared by dissolving 1 $\mathrm{mg} \mathrm{DQ}^{\mathrm{TM}}$ gelatin in $1.0 \mathrm{ml}$ Milli-Q water, and this was further diluted 1:50 in the developing buffer containing $50 \mathrm{~mm}$ Tris- $\mathrm{HCl}$, $200 \mathrm{~mm} \mathrm{NaCl}, 5 \mathrm{mM} \mathrm{CaCl}_{2}$, and $0.02 \%$ (w/v) Brij 35. Fifty microliters of this mixture was put on tissue sections and incubated in a dark humidity chamber for $2 \mathrm{~h}$ at $37^{\circ} \mathrm{C}$. Sections were then rinsed in PBS. To verify the contribution of metalloproteases, control slides were preincubated with $20 \mathrm{mM}$ EDTA for $1 \mathrm{~h}$, and $20 \mathrm{~mm}$ EDTA was also added to the substrate. The level of autofluorescence in the tissue was evaluated by incubating the control section after the developing buffer was added.

\section{RNA Purification and $q P C R$}

RNA extraction from explanted scaffolds was performed using an RNeasy Mini Kit (QIAGEN VWR, Stockholm, Sweden) following the manufacturer's instructions. The RNA concentration of each sample was determined using a Quant-iT ${ }^{\text {тм }}$ RiboGreen ${ }^{\circledR}$ RNA Reagent and Kit (Invitrogen Co., Carlsbad, Calif., USA) according to the manufacturer's instructions. Reverse transcription was carried out with a $50-\mu$ l total volume containing $1 \mu \mathrm{g}$ RNA, $5 \mu \mathrm{l} 10 \times$ TaqMan RT buffer, $11 \mu \mathrm{l} \mathrm{MgCl}_{2}(25 \mathrm{~mm}), 10$ $\mu \mathrm{l}$ dNTP mixture (10 mM), $2.5 \mu \mathrm{l}$ random hexamer $(50 \mathrm{mM}), 1 \mu \mathrm{l}$ RNase inhibitor $(20 \mathrm{U} / \mu \mathrm{l})$, and $1.25 \mu \mathrm{l}$ reverse transcriptase (50 U/ $\mu \mathrm{l}$ ) (Applied Biosystems, Foster City, Calif., USA). RNAse-free 
1 week
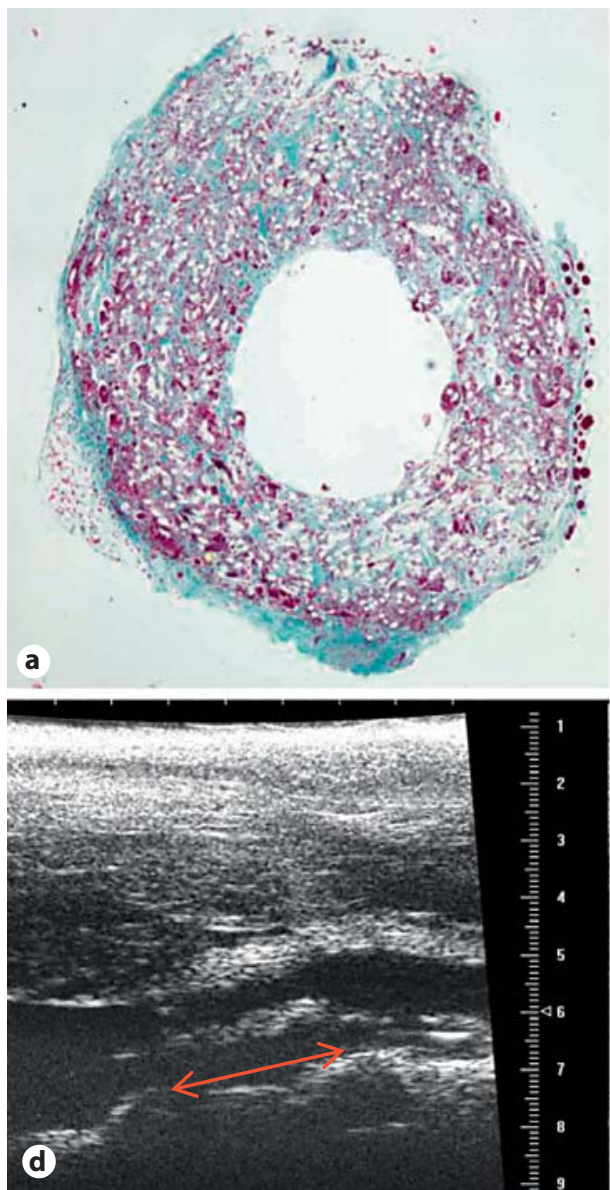

2 weeks
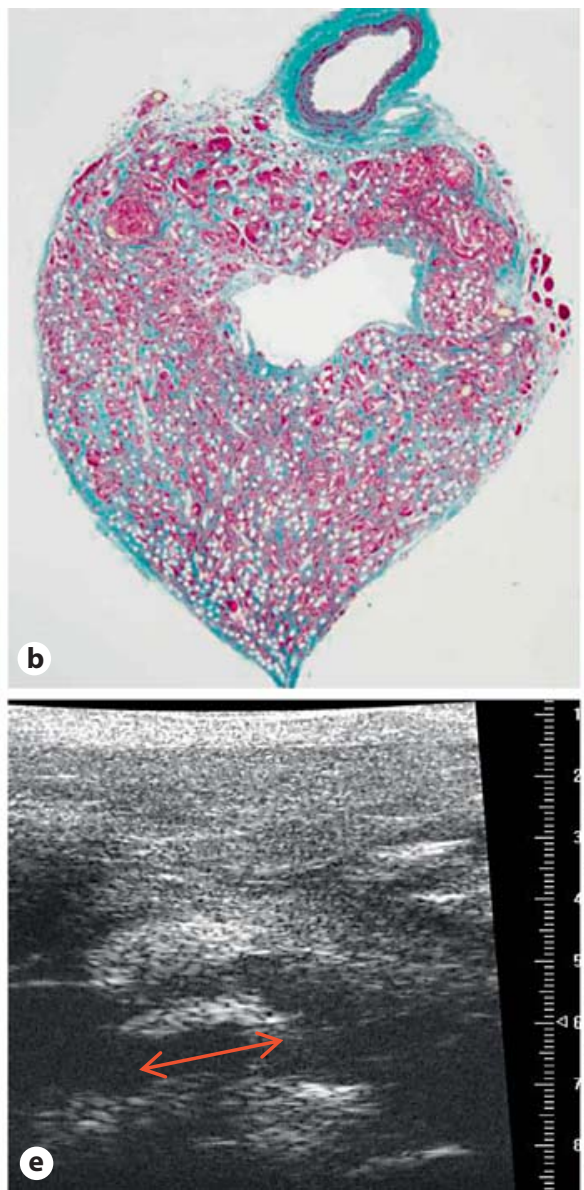

4 weeks
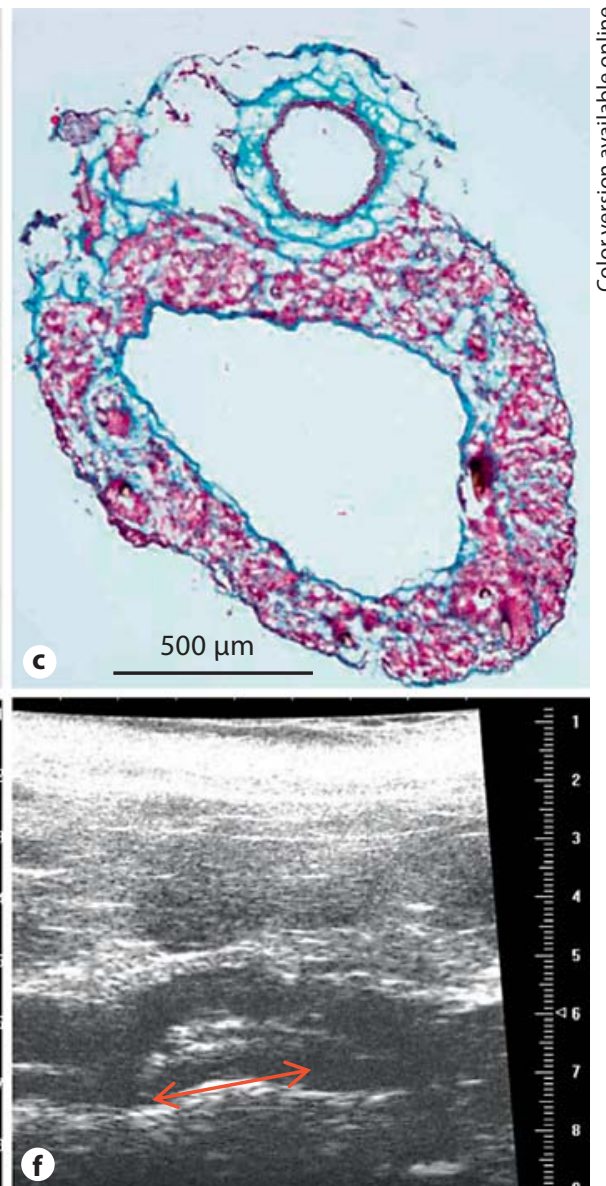

Fig. 1. Time course change in TEVG. Masson's trichrome staining (a-c) and ultrasound pictures (d-f). Arrows indicate scaffolds. Histological evaluation of the TEVG over a 4-week time course revealed progressive neotissue formation characterized by cellular infiltration, ECM deposition, and remodeling (a-c).

water was added up to $50 \mu l$. Thermal cycling parameters included incubation at $25^{\circ} \mathrm{C}$ for $10 \mathrm{~min}$, reverse transcription at $48^{\circ} \mathrm{C}$ for $30 \mathrm{~min}$, and inactivation at $95^{\circ} \mathrm{C}$ for $5 \mathrm{~min}$. Predesigned and validated gene-specific TaqMan Gene Expression Assays from Applied Biosystems were used in duplicate for quantitative realtime PCR according to the manufacturer's instructions. The genes of interest for analysis included type I collagen (Colla2, Mm00483888_m1), type III collagen (Col3a1, Mm01254458_g1), type IV collagen (Col4a3, Mm01269207_m1), elastin (Eln, Mm00514692_m1), decorin (Dcn, Mm01223999_m1), versican (Mm00490174_m1), MMP-9 (Mmp9, Mm01240563_g1), and MMP-2 (Mmp2, Mm00439498_m1) (Applied Biosystems). Realtime PCR reactions were carried out in 96-well reaction plates in the iCycler iQ Real-Time PCR Detection System (Bio-Rad) following the manufacturer's instructions. Relative expression levels were determined from collected data as threshold cycle numbers. Hypoxanthine-guanine phosphoribosyltransferase (HPRT) was used as an endogenous control.

\section{Statistics}

All data are presented as means \pm SD. Data were compared using Student's t test and one-way ANOVA. Post hoc tests were conducted as multiple comparisons using either Fisher's PLSD test or Scheffé's test according to the distribution of the data.

\section{Results}

\section{Morphology}

Serial ultrasound evaluation demonstrated that all TEVGs were patent. Histological evaluation over the 4-week time course revealed progressive neotissue formation characterized by cellular infiltration, ECM deposition, and remodeling (fig. 1). Scaffold degradation in vivo was visualized using a polarized microscope (fig. 2). The visible fiber number and size were decreased over time. 

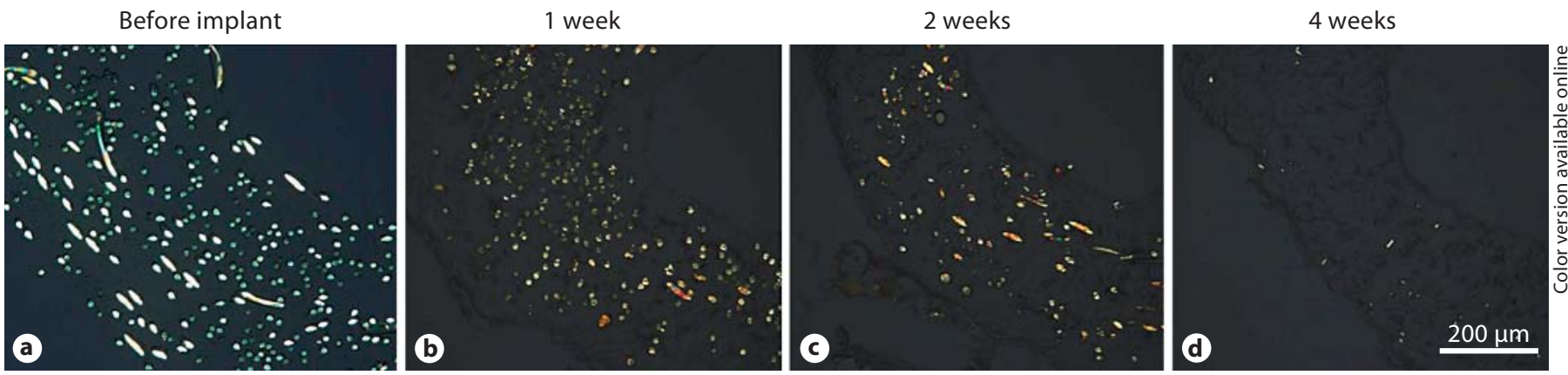

Fig. 2. Scaffold degradation in vivo visualized using a polarized microscope (a-d). The visible fiber number and size decreased over time.

Collagen

Masson's trichrome staining highlighted collagen, which was associated with scaffold material over the 4 -week study period. Abundant collagenous fibers formed between the polymer at early time points (fig. 3a, b), but these fibers lost their volume by 4 weeks (fig. 3c). A thin layer of collagen fibers was also noted in the medial layer of the neovessel (fig. 3c). IHC revealed an initial increase in type III collagen deposited between the scaffold fragments (fig. 3i, j) followed by type I collagen deposition (fig. 3e, f). Both type III and type I collagen deposited between scaffold fragments disappeared by 4 weeks, but a thin layer consisting of both types of collagen formed within the medial layer of the neovessel (fig. 3g, k). Type IV collagen was not detected at the luminal surface of the neovessel until the 4-week time point. When viewed using polarized light (dark-field microscopy), Picrosirius red staining revealed larger collagen fibers (possibly type I collagen) as bright yellow or orange and thinner fibers (possibly type III collagen) as green. At the 4 -week time point, the predominant collagen was type I (fig. 3o). Figure 4 illustrates changes in gene expression of the collagen subtypes over the course of TEVG neovessel formation. The results indicate the trend of early induction of collagen gene expression at 1 week, which peaked for both type I and type III collagen at 2 weeks. The levels of gene expression for both collagen I and collagen III were significantly greater than those for the normal vena cava; however, there was no statistical difference at 4 weeks, which suggests that neovessl collagen gene expression will approximate that of native tissue at 4 weeks. The expression of type IV collagen was significantly lower at early time points (1 and 2 weeks) compared to that of normal vena cava and then approximated that of vena cava at 4 weeks. Total collagen quantified by a hydroxyproline assay indicated that the trend of total collagen in the TEVG peaked at 2 weeks. There was statistical significance between 2 -week TEVG and normal vena cava, but the collagen content was equivalent between the 4-week TEVG and normal vena cava. This suggests that the amount collagen in the neovessel will approximate that of vena cava at 4 weeks (fig. $4 \mathrm{~d})$.

\section{Elastin}

A faint stain suggested elastic fibers near the luminal surface of the neovessels at 4 weeks. Fibrillin-1 (which presumably serves as a template for tropoelastin deposition) was upregulated during early time periods (fig. 5eg). Figure $5 \mathrm{i}$ and $\mathrm{j}$ shows associated changes in the gene expression for elastin and fibrillin-1 at different times during TEVG neovessel formation. Note that the gene expression of elastin increased over time throughout the entire study period; in contrast, that of fibrillin-1 was higher than that of elastin at early time points but then decreased at 4 weeks. Overall, elastin protein production increased over time in the neovessels.

Fig. 3. Characterization of collagen subtypes by histology. Masson's trichrome stain (a-d), IHC of type I (e-h), type III (i-I), and type IV (q-t) collagens, and Picrosirius red staining $(\mathbf{m}-\mathbf{p})$ demonstrated changes in the deposition of each collagen type over time. The layer between the arrows indicates the medial layer of each neovessel (c, $\mathbf{g}, \mathbf{k})$. 

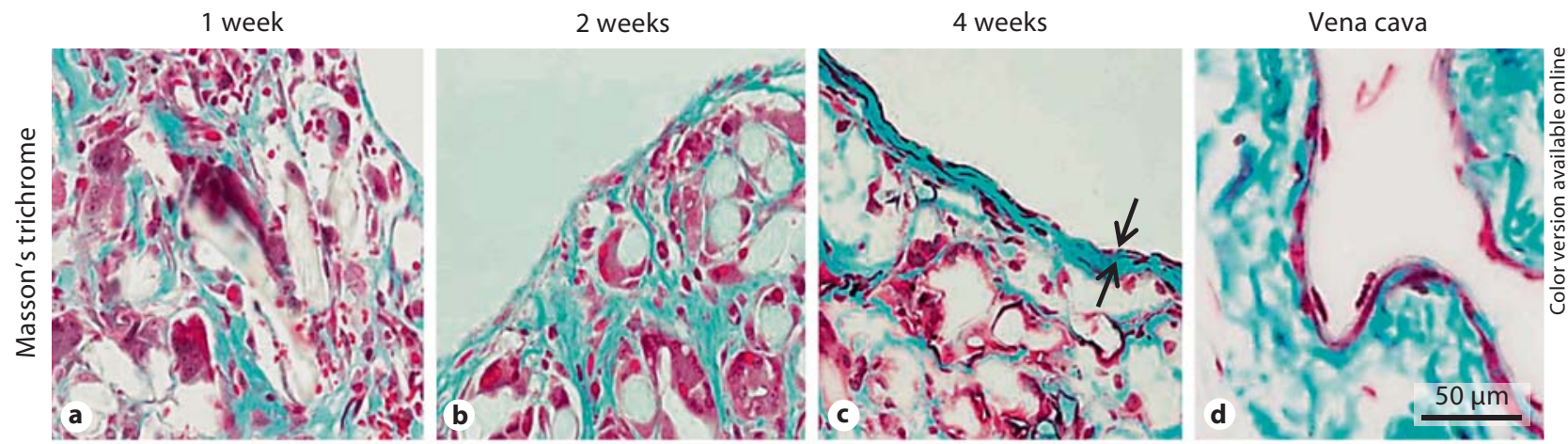

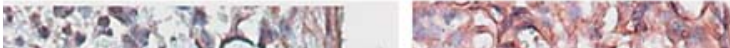

g.

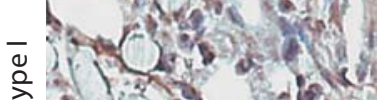

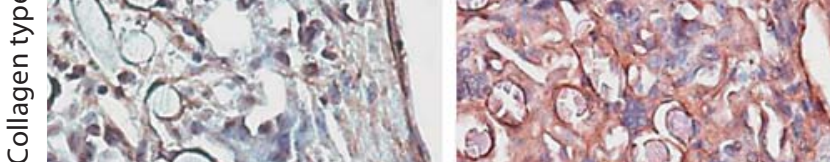
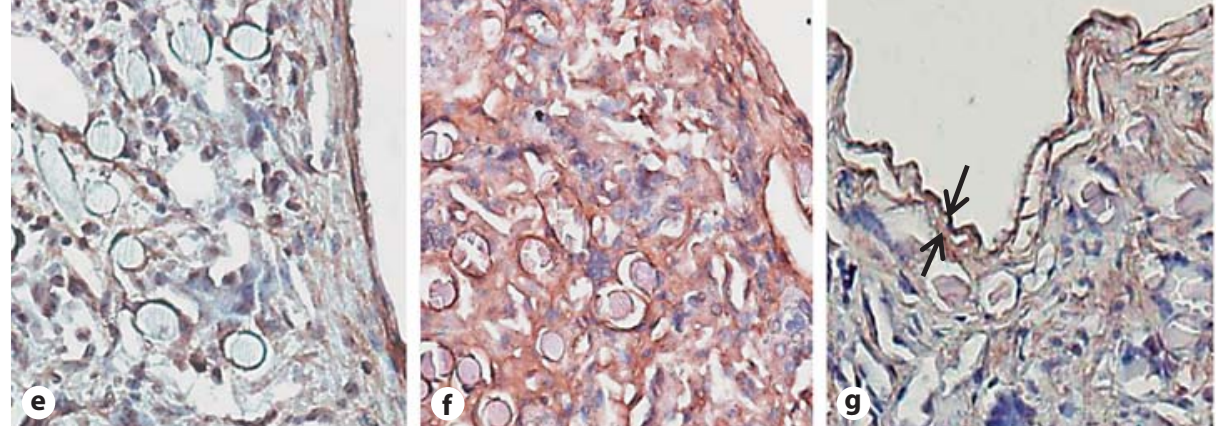

e $\cos ^{2}$.
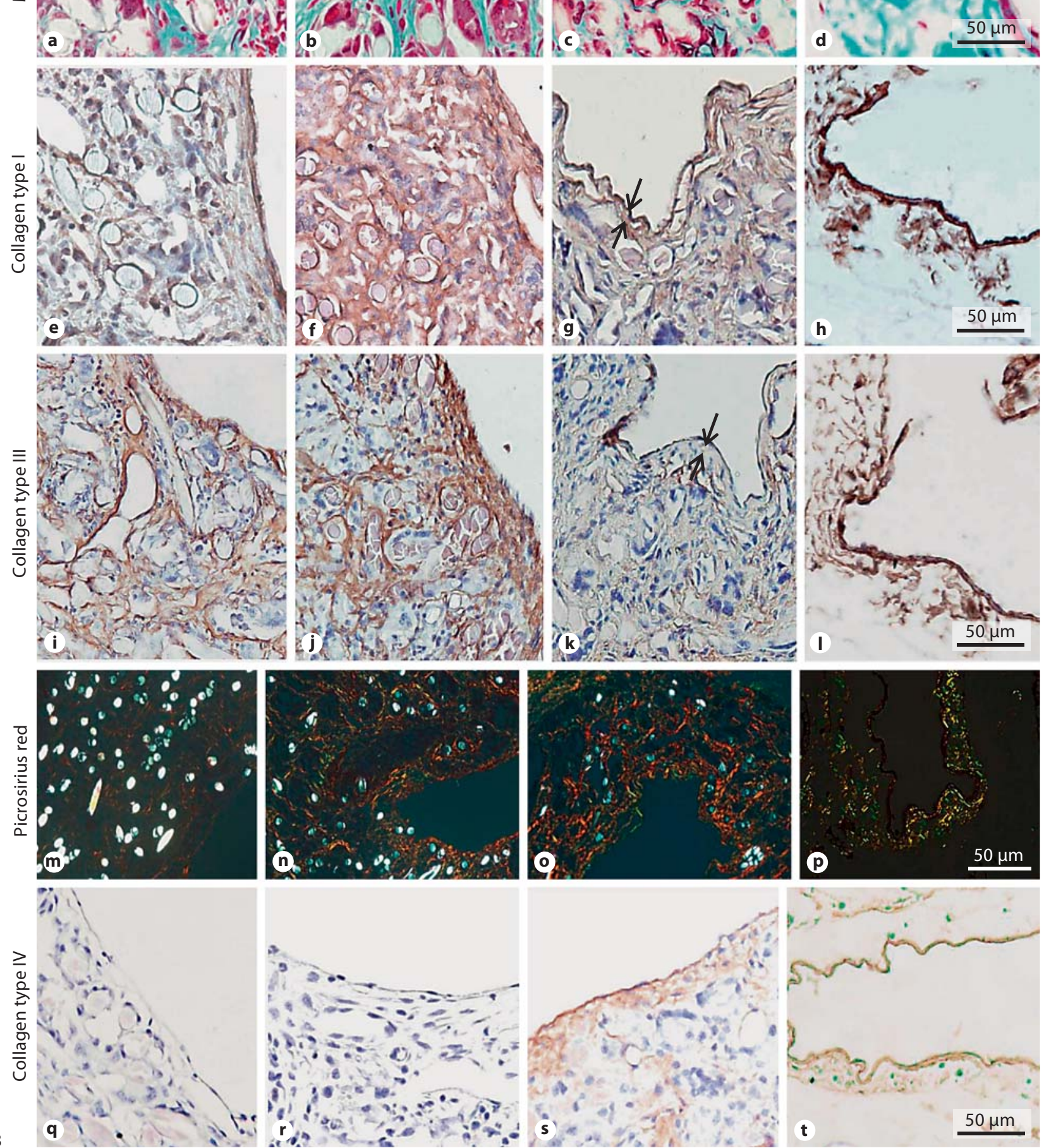

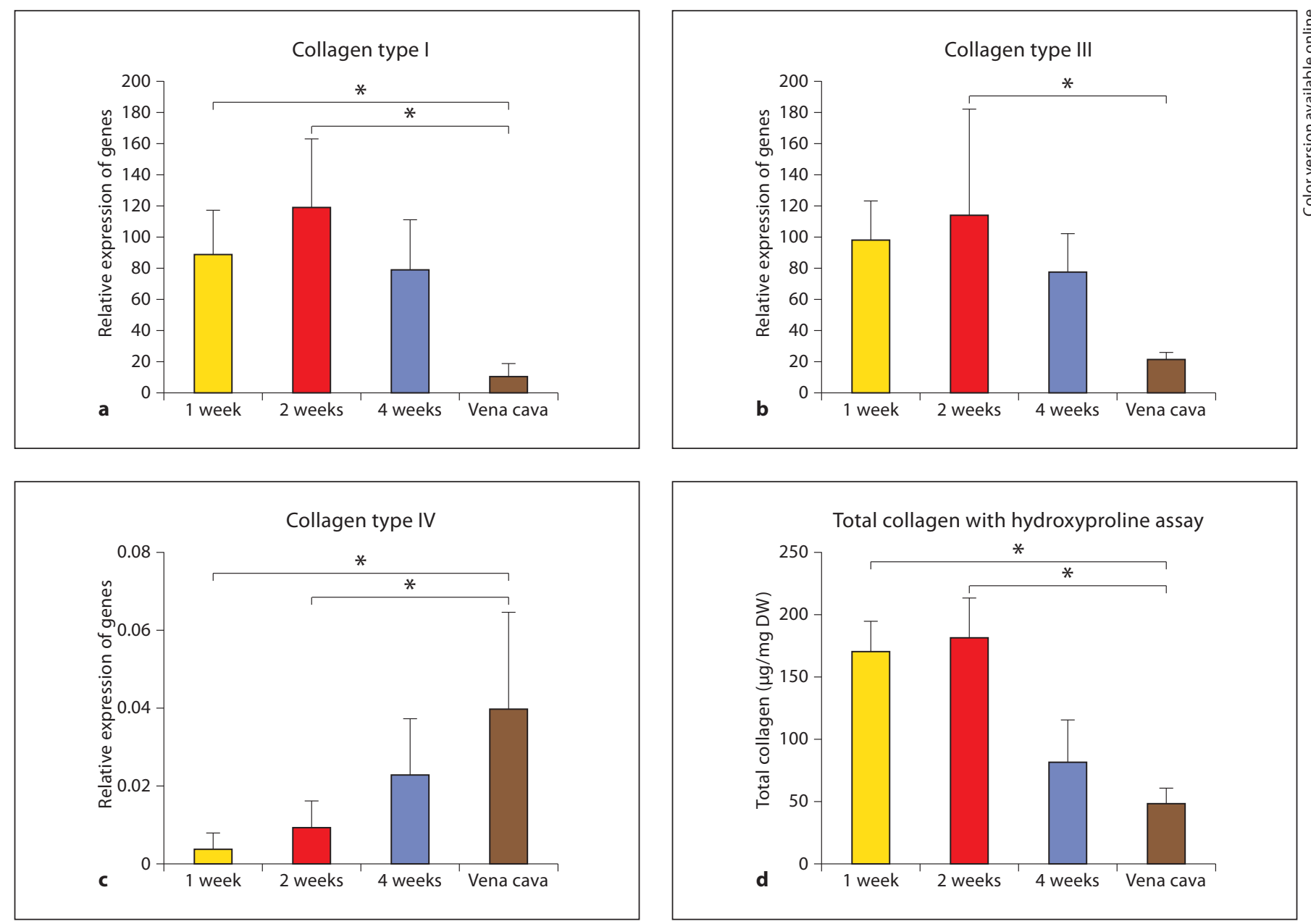

Fig. 4. Collagen gene expression. Gene expression characterization of collagen subtypes (a-c) and biochemical quantification of total collagen (d) (* $\mathrm{p}<0.05, \mathrm{n}=6$ for gene expression and $\mathrm{n}=3$ for biochemical assay). Gene expression of collagen types I (a) and III (b) and the total collagen trended toward peaks at the 2-week time point. The level of gene expression and amount of collagen approach those of normal vena cava at the 4-week time point. The expression of type IV collagen gene (c) was significantly lower at early time points compared to that of vena cava; however, it approached that of normal vena cava at the 4-week time point. DW = Dry weight.

\section{GAG/Proteoglycans}

Alcian blue staining revealed the appearance of sulfated GAG in the neovessels at each time point during neovessel formation (fig. 6a-c). Figure 6e and f demonstrates further that the gene expression of proteoglycans differed depending on the type: there was a significant increase in decorin gene expression at the 4 -week time point but no significant change in versican gene expression during the study period. Gene expression for both decorin and versican was higher in the neovessels than in vena cava, however. Finally, the Blyscan GAG assay demonstrated that there was an overall significant increase in the production of GAG in the neovessels at 4 weeks compared to earlier time points (fig. $6 \mathrm{~g}$ ).

\section{ECM Remolding by MMPs}

Histology showed robust production of MMP-2 at each time point (fig. 7a-c), whereas MMP-9 expression decreased over time (fig. 7e-g). MMP-9 initially appeared adjacent to scaffold fragments but shifted towards the luminal surface over time to more closely approximate expression of MMP-9 in normal vena cava. Gene expression of MMP-2 increased significantly (fig. 7i), while that for MMP-9 decreased significantly at 4 weeks (fig. 7j). Figure 

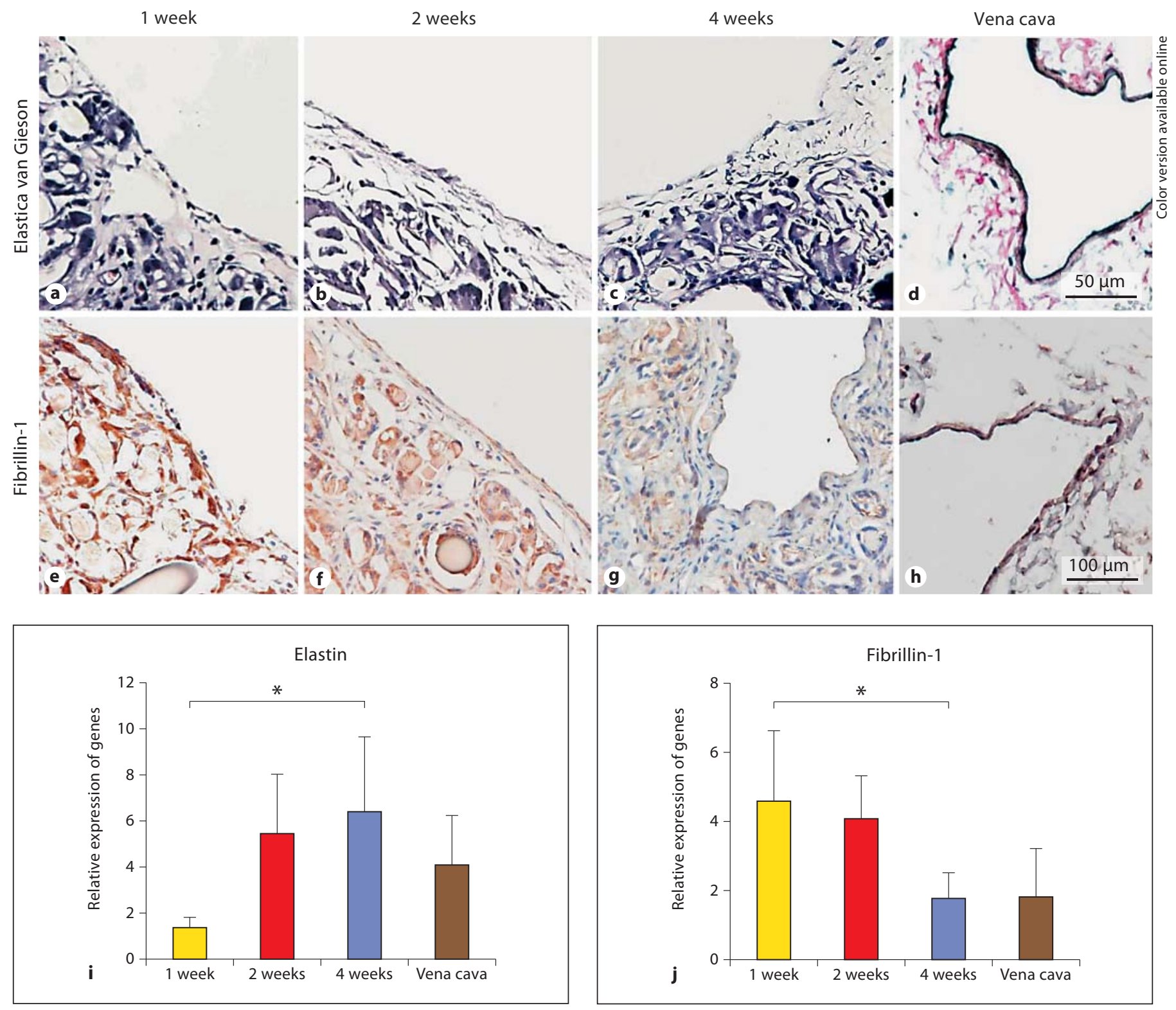

Fig. 5. Characterization of elastin and its associated microfibril. The faint stain suggested elastic fibers formed on the luminal surface of neovessel at 4 weeks. Fibrillin-1 was upregulated during early time periods $(\mathbf{e}-\mathbf{g})$. Our results showed that gene expression (i) and production (k) of elastin increased over time throughout the entire study period. The gene expression of fibrillin-1 (j) preceded that of elastin and decreased over time $\left({ }^{*} \mathrm{p}<0.05, \mathrm{n}=6\right.$ for gene expression and $n=3$ for biochemical assay). DW $=$ Dry weight.

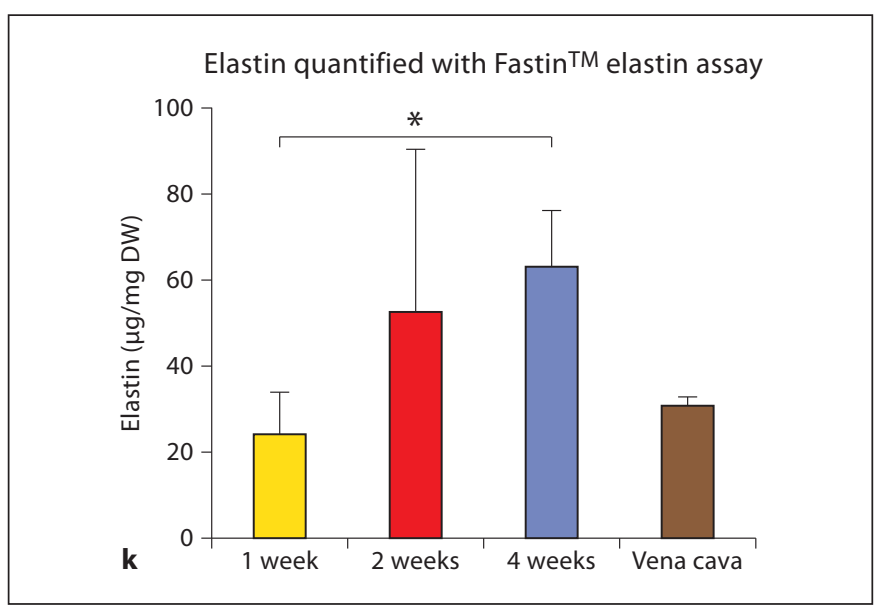



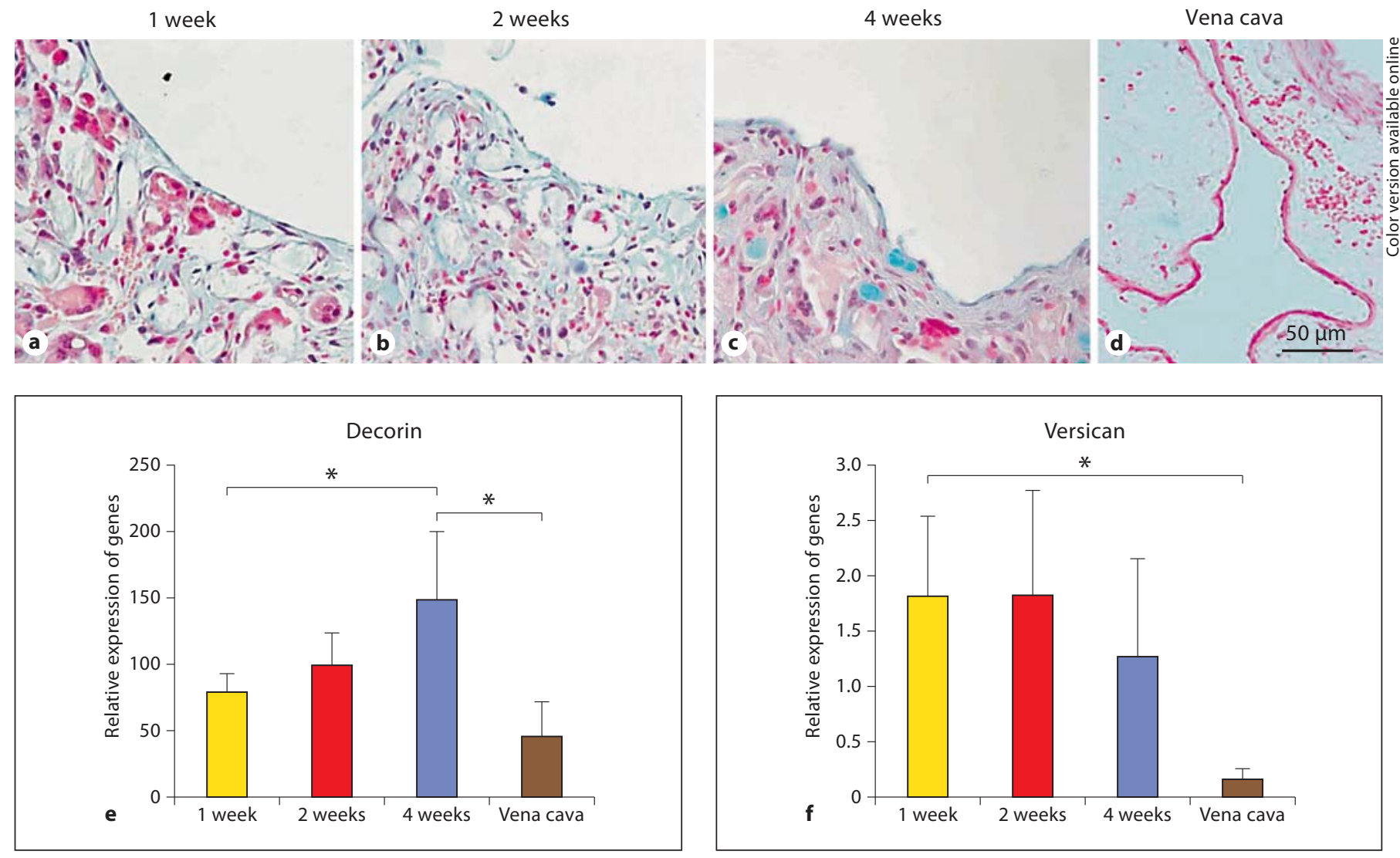

Fig. 6. Characterization of GAG/proteoglycans. Sulfated GAG, stained blue, were abundantly seen at each time point during neovessel formation $(\mathbf{a}-\mathbf{c})$. A significant increase in decorin gene expression (e) was observed at the 4 -week time point, whereas there was no significant change in gene expression in versican (f). There was a significant increase in the production of GAG at the 4 -week time point compared to the 1- or 2-week time point $(\mathbf{g})$ ( ${ }^{*} \mathrm{p}<0.05, \mathrm{n}=6$ for gene expression and $\mathrm{n}=3$ for biochemical assay). DW $=$ Dry weight.

$8 \mathrm{a}, \mathrm{b}$, and $\mathrm{c}$ shows an in situ zymogram of neovessels at different time points. The enzymatic activity first appeared around scaffold fragments and then shifted to the luminal surface at 4 weeks. Figure $8 \mathrm{~d}$ is a substrate zymogram, which demonstrates the gelatinolytic activity of neovessels at different time points. MMP-9 activity was detectable up to 4 weeks but showed variability between samples. MMP2 activity was consistently detectable up to 4 weeks.

\section{Endothelization and Smooth Muscle Cell Layer}

\section{Formation}

The luminal surface was completely covered by CD31positive cells and lined with a-SMA-positive cells at the 4-week time point (fig. 9c, g, o). 

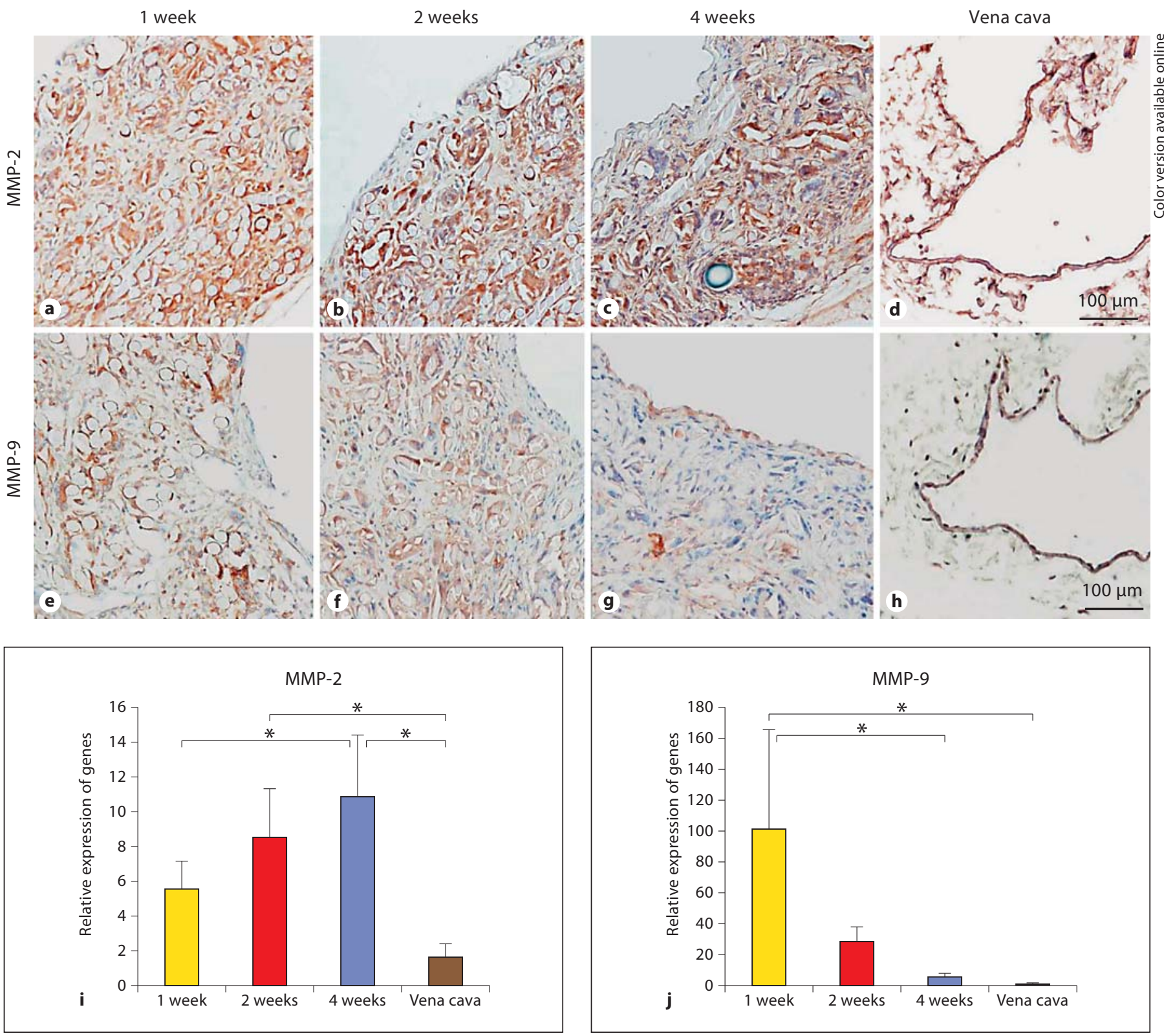

Fig. 7. Characterization of MMPs by histology. Histology showed robust production of MMP-2 at each time point (a-c), whereas MMP-9 decreased over time (e-g). Gene expression of MMP-2 significantly increased at 4 weeks (i), whereas MMP-9 significantly decreased at the 4 -week time point $(\mathbf{j})\left({ }^{*} \mathrm{p}<0.05, \mathrm{n}=6\right)$.

\section{Discussion}

Our previous work characterizing the ECM of neotissue in our TEVG was limited to a comparison of the fully formed neovessel to its corresponding native blood vessel [Brennan et al., 2008]. From these studies we determined that the composition of neovessel ECM reca- pitulates that of native blood vessels and is composed primarily of collagen, elastin, and GAG.

There is an important and related report which describes ECM gene expression in tissue-engineered vessels cultured in a pulsatile bioreactor setting [HeydarkhanHagvall et al., 2006]. This investigation characterized for the first time the dynamic process of ECM deposition 

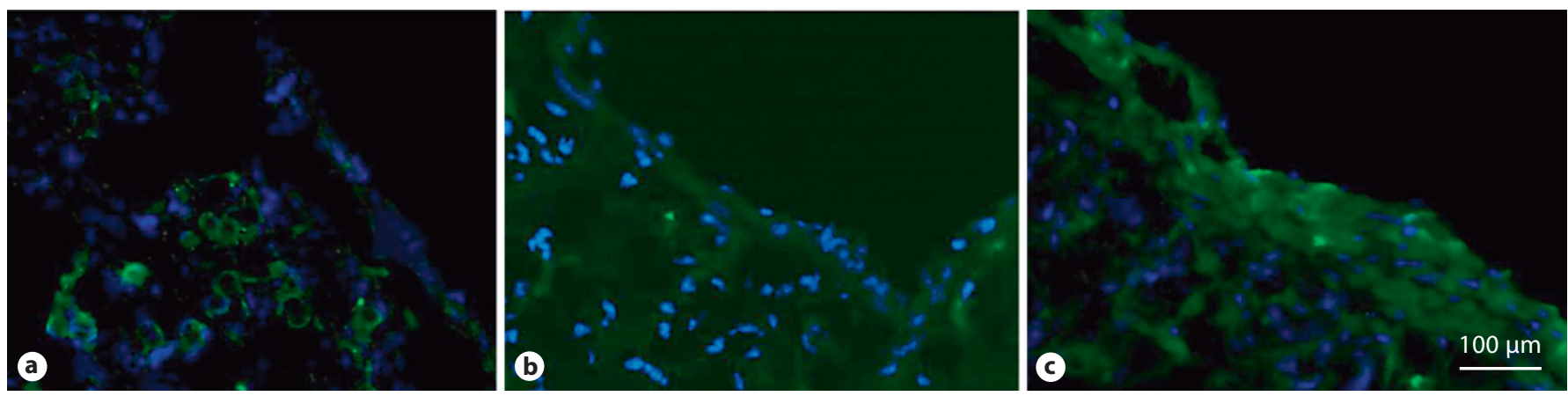

Fig. 8. Enzymatic activity of MMPs by gelatin zymogram. The enzymatic activity of neovessels first appeared around scaffold fragments (a) and then shifted to the luminal surface at the 4 -week time point (c). Green = Gelatinase activity; blue = DAPI. d Substrate zymograms which demonstrate gelatinolytic activity of neovessels at different time points $\left({ }^{*} \mathrm{p}<0.05, \mathrm{n}=6\right)$.

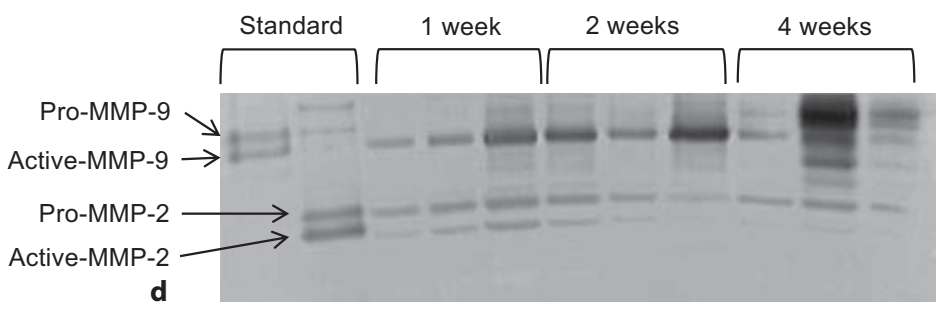

1 week
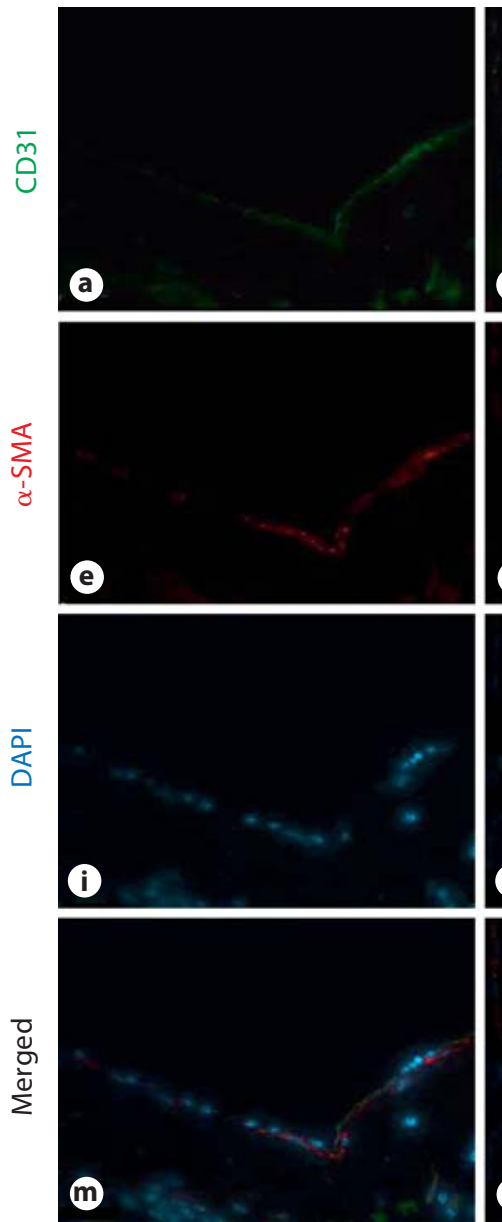

2 weeks
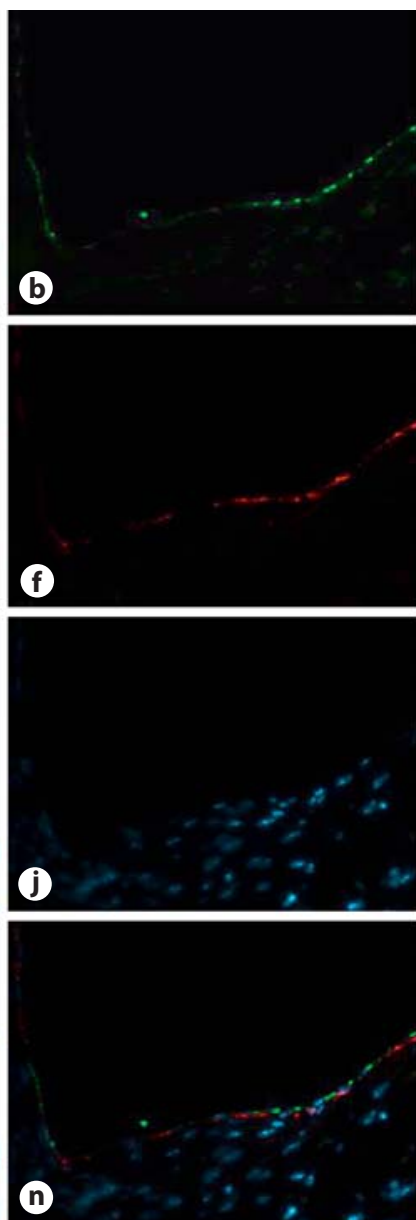

(n)
4 weeks
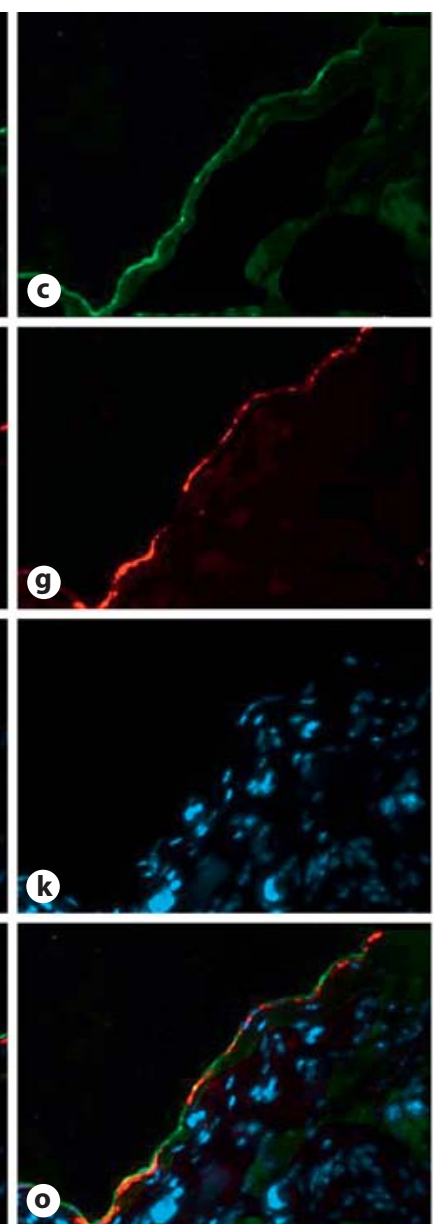

Vena cava

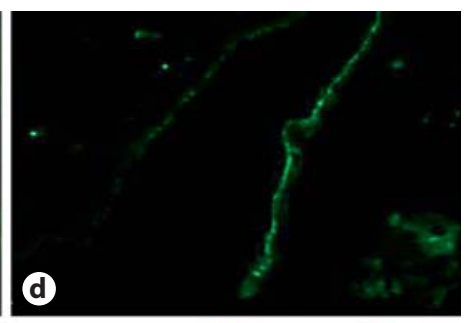

(b)

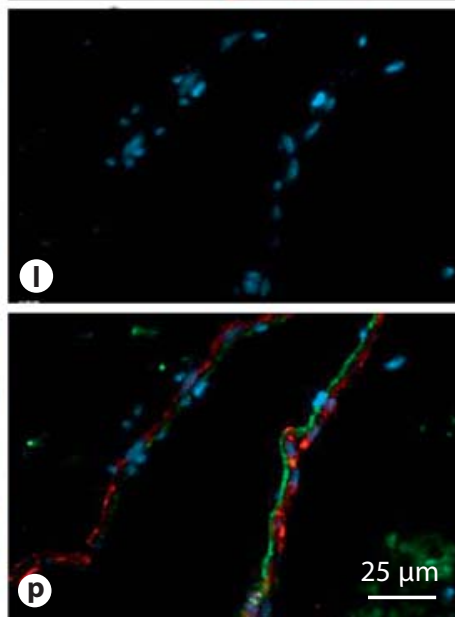

Fig. 9. Endothelization and smooth muscle cell layer formation. The luminal surface of the neovessel was completely endothelialized with a single layer of smooth muscle cells at the 4-week time point (c, g, o). 
and scaffold degradation over a 4-week period in vivo. Our results from both IHC and Picrosirius red staining demonstrated that type III collagen dominated the early phase of neovessel formation and was followed by type I collagen synthesis. Overall, there appeared to be a marked early production of the fibrillar collagens but a reduction thereafter that tracked the rapid loss of polymer (fig. 2, $4 \mathrm{~d})$. In contrast, collagen IV, elastin, and total GAG all tended to increase during the 4-week study period, contrasting with the time-dependent loss of polymer. It may be that the initial surge in collagen production reflected a cellular response to isolate the polymer, which waned as the polymer degraded. As the polymer degraded, however, hemodynamic-induced stresses were likely transferred from the polymer to the nascent ECM and cells, which in turn may have stimulated neotissue development. This might include elastin production that followed fibrillin-1 production and decorin production that favors a more orderly assembly and growth of collagen fibrils, which in turn could have facilitated a more normal overall tensile stiffness and strength. ECM stiffness is an important determinant of cell mechanobiology, including differentiation status, and tensile strength is fundamental to ensuring adequate structural integrity in the presence of hemodynamic and other applied loads. In particular, decorin stabilizes the fibrillar matrix in vivo [Danielson et al., 1997].

Based on qPCR results of elastin gene expression, it appears that elastogenesis started early (1 week) but continued to increase over time. Upregulation of fibrillin-1 gene expression at early time points is presumably in accordance with basic mechanisms of elastogenesis in early development, in which tropoelastin (the soluble precursor of mature elastin) is deposited on a preformed template of fibrillin-rich microfibrils [Mecham and Davis, 1994]. Although it is well known that elastin synthesis by smooth muscle cells can be stimulated by cyclic stretching, there is a need for further investigation to determine if increased elastin expression in these IVC interposition grafts was induced by incremental increases in stretch experienced by the vascular smooth muscle cells as the scaffold degraded and collagen was synthesized [Sutcliffe and Davidson, 1990].

Our PCR results demonstrated an increase in gene expression of MMP-9 in the earliest phase of neovessel formation but a decrease thereafter; in contrast, expression of MMP-2 simply increased over time. These trends are similar to what is normally found in vascular injury models [Bendeck et al., 1994; Godin et al., 2000]. MMP-9 is reported to stimulate the migration of inflammatory cells and myofibroblasts in vascular injury [Zalewski and Shi, 1997; Inoue et al., 2010]. In addition, MMP-9 is known as the most prominent type of MMP present in a foreign body inflammatory response [Jones et al., 2008]. Another role for MMP-9 in TEVG remodeling might be related to the development of stenosis since a certain level of MMP-9 was reported to induce contraction of collagen fibers by smooth muscle cells [Defawe et al., 2005]. The increase in MMP-2 over time during neovessel remodeling appears to be consistent with the fact that MMP-9 originates from macrophages, whereas MMP-2 is mainly produced by resident mesenchymal cells when stimulated by inflammatory cells [Davis et al., 1998]. We speculate that the incremental migration of smooth muscle cells in the TEVG correlates with the production of MMP-2. The presumptive role of MMP-2 and MMP-9 in TEVG neovessel remodeling includes induction of an early inflammatory response evoked by a foreign body reaction as well as ECM degradation to adapt to the mechanobiological/physiological milieu.

Whether activation of the latent form of MMP involves tissue inhibitors of metalloproteinases (TIMPs), which play a role in the TEVG remodeling process, warrants further investigation. Regulation of MMPs may occur at multiple levels via gene transcription and synthesis of inactive proenzymes, posttranslational activation of proenzymes, or the interaction of secreted MMPs with TIMPs [Raffetto et al., 2008]. Our results showed decreased activation of both MMP-2 and MMP-9 in later time points during neovessel formation. Considering that peak collagen production occurs at 2 weeks and is followed by decreased activation of each MMP, one may speculate that organized ECM deposition could regulate MMP activation by either biochemical or biomechanical remodeling

ECM is the primary determinant of the structural integrity of the vascular wall and it determines the mechanical environment in which the cells reside. Because all vascular cells are highly responsive to changes in their local mechanical environment [Humphrey, 2008], the importance of the evolving mechanobiological environment cannot be underestimated. ECM deposition and remodeling is thus a critical component of normal neovessel formation as well as increased load bearing as the polymer scaffold degrades. In this investigation, we provide some of the first qualitative and quantitative data describing this process. Descriptive work of this nature is critical as we seek to better understand the process of neotissue formation, particularly what biochemical and biomechanical cues elicit optimal cellular responses. Im- 
proving our understanding of the process of neovessel formation will thus form the basis for rationally designing improved second-generation TEVG, which should be designed so that their evolving structural integrity minimizes the compliance mismatch with host vessels. The evolving local mechanical environment permits optimal cellular responses, particularly those fundamental to endowing the neovessel with the ability to continue to grow and adapt in response to hemodynamic loads that change as a child grows.

\section{Acknowledgements}

Funding for this project was provided by NIH K08HL083980 and NIH R01HL098228. The authors would like to thank Sandra Canossa for her technical assistance with zymography procedures.

\section{References}

Bendeck, M.P., N. Zempo, A.W. Clowes, et al. (1994) Smooth muscle cell migration and matrix metalloproteinase expression after arterial injury in the rat. Circ Res 75: 539545.

-Brennan, M.P., A. Dardik, N. Hibino, et al. (2008) Tissue-engineered vascular grafts demonstrate evidence of growth and development when implanted in a juvenile animal model. Ann Surg 248: 370-377.

Danielson, K.G., H. Baribault, D.F. Holmes, et al. (1997) Targeted disruption of decorin leads to abnormal collagen fibril morphology and skin fragility. J Cell Biol 136: 729-743.

-Davis, V., R. Persidskaia, L. Baca-Regen, et al. (1998) Matrix metalloproteinase-2 production and its binding to the matrix are increased in abdominal aortic aneurysms. Arterioscler Thromb Vasc Biol 18: 1625-1633.

Defawe, O.D., R.D. Kenagy, C. Choi, et al. (2005) MMP-9 regulates both positively and negatively collagen gel contraction: a nonproteolytic function of MMP-9. Cardiovasc Res 66: 402-409.

-Godin, D., E. Ivan, C. Johnson, et al. (2000) Remodeling of carotid artery is associated with increased expression of matrix metalloproteinases in mouse blood flow cessation model. Circulation 102: 2861-2866.

-Heydarkhan-Hagvall, S., M. Esguerra, G. Helenius, et al. (2006) Production of extracellular matrix components in tissue-engineered blood vessels. Tissue Eng 12: 831-842.

-Hibino, N., E. McGillicuddy, G. Matsumura, et al. (2010) Late-term results of tissue-engineered vascular grafts in humans. J Thorac Cardiovasc Surg 139: 431-436, 436.e1-2.
Humphrey, J.D. (2008) Vascular adaptation and mechanical homeostasis at tissue, cellular, and sub-cellular levels. Cell Biochem Biophys 50: 53-78.

Inoue, T., I. Taguchi, S. Abe, et al. (2010) Activation of matrix metalloproteinase- 9 is associated with mobilization of bone marrow-derived cells after coronary stent implantation. Int J Cardiol, E-pub ahead of print.

Jones, J.A., A.K. McNally, D.T. Chang, et al. (2008) Matrix metalloproteinases and their inhibitors in the foreign body reaction on biomaterials. J Biomed Mater Res A 84: 158166.

Madri, J.A., F.J. Roll, H. Furthmayr, et al. (1980) Ultrastructural localization of fibronectin and laminin in the basement membranes of the murine kidney. J Cell Biol 86: 682-687.

Matsumura, G., Y. Ishihara, S. Miyagawa-Tomita, et al. (2006) Evaluation of tissue-engineered vascular autografts. Tissue Eng 12: 3075-3083.

Matsumura, G., S. Miyagawa-Tomita, T. Shin' oka, et al. (2003) First evidence that bone marrow cells contribute to the construction of tissue-engineered vascular autografts in vivo. Circulation 108: 1729-1734.

Mecham, R.P., E.C. Davis: Elastic fiber structure and assembly; in Yurchenko, P.D., D.E. Birk, R.P. Mecham (eds): Extracellular Matrix Assembly and Structure. San Diego, Academic Press, 1994, pp 281-314.

Nelson, G.N., T. Mirensky, M.P. Brennan, et al. (2008) Functional small-diameter human tissue-engineered arterial grafts in an immunodeficient mouse model: preliminary findings. Arch Surg 143: 488-494.
Raffetto, J.D., R.A. Khalil (2008) Matrix metalloproteinases in venous tissue remodeling and varicose vein formation. Curr Vasc Pharmacol 6: 158-172.

Roh, J.D., G.N. Nelson, M.P. Brennan, et al. (2008) Small-diameter biodegradable scaffolds for functional vascular tissue engineering in the mouse model. Biomaterials 29: 1454-1463.

Roh, J.D., R. Sawh-Martinez, M.P. Brennan, et al. (2010) Tissue-engineered vascular grafts transform into mature blood vessels via an inflammation-mediated process of vascular remodeling. Proc Natl Acad Sci USA 107: 4669-4674

Samuel, C.S. (2009) Determination of collagen content, concentration, and sub-types in kidney tissue. Methods Mol Biol 466: 223 235.

Shin'oka, T., Y. Imai, Y. Ikada (2001) Transplantation of a tissue-engineered pulmonary artery. N Engl J Med 344: 532-533.

Shin'oka, T., G. Matsumura, N. Hibino, et al. (2005) Midterm clinical result of tissueengineered vascular autografts seeded with autologous bone marrow cells. J Thorac Cardiovasc Surg 129: 1330-1338.

Sutcliffe, M.C., J.M. Davidson (1990) Effect of static stretching on elastin production by porcine aortic smooth muscle cells. Matrix 10: $148-153$.

Zalewski, A., Y. Shi (1997) Vascular myofibroblasts: lessons from coronary repair and remodeling. Arterioscler Thromb Vasc Biol 17: 417-422. 